\title{
Private Labels, National Brands and Food Prices
}

\author{
Christophe Bontemps, Valérie Orozco \\ Toulouse School of Economics (GREMAQ-INRA) \\ \& Vincent Réquillart \\ Toulouse School of Economics (GREMAQ-INRA, \& IDEI)
}

January 11, 2008

\begin{abstract}
We study the relationships between national brand prices and the development of private labels, using home-scanned data from a consumer survey reporting purchases for 218 food products. In a significant number of cases (144 out of 218), we observe a positive correlation (89\%) between brand price and purchases of private labels. When controlling for changes in the products quality, we still find a positive relation between private label development and national brand prices. Thus, the change in the national brand product characteristics only partly explains the increase in the national brand prices. Furthermore, the price reactions of national brands differ according to the type of private labels they are facing. Finally, we demonstrate that the development of private labels has less effect on the prices of second-tier brands than prices of the leading brand.
\end{abstract}

Keywords : private labels, pricing, empirical models, food products.

JEL : L81, Q13, D40 


\section{Introduction}

Retailers play a key role in the food chain. For example, in France, they sell about $75 \%$ of food products to final consumers (INSEE, 2004). Among other decisions, they set consumer prices and determine the assortment of goods to be sold. By developing private labels (PL), which are their own brands, retailers now play an active role in the production of final goods 1 These products, which now represent $10 \%$ to $40 \%$ of retail food sales in the different EU countries, are a strategic tool used by retailers to increase profits.

Private labels provide additional market power to retailers. Thus, by developing their own products, retailer are less dependent on the upstream suppliers. By lowering their dependency, retailers reinforce their bargaining position and can thus extract more profits. By developing their own products, they also obtain more information about upstream costs. This is another way of reinforcing bargaining power since it is liable to reduce information rents. Private labels also modify the competition among retailers. Because a private label is a specific product of a given retailer, retailers use it as a differentiation tool, which thus potentially softens the price competition among them. Private labels also allow retailers to attract customers and build up store loyalty.

However, the effect of private label development on prices remains an open question. Theoretical models have mainly addressed this question in terms of a vertical structure between producers and retailers. The impact of private label development on national brand (NB) prices is different according to the method used to model demand and the form of the contract 2 The conventional wisdom is that PL entry induces a decrease in the NB prices. Moreover, empirical models provide different answers. For example, Ward et al. (2002) found that private label development has a positive impact on national brand prices. These authors obtained a systematic relationship across a large number of food product categories. On the other hand, Bonfrer and Chintagunta (2004) obtained some mixed results on the changes of national brand prices following the introduction of private labels and found a negative price impact in $46 \%$ of cases.

As a new product, the introduction of PL impacts consumer surplus. If NB prices increase with PL entry, then their entry could negatively affects consumer

\footnotetext{
${ }^{1}$ According to the Private Label Manufacturers' Association (PLMA), "[Private label] products encompass all merchandise sold under a retailer's brand. That brand can be the retailer's own name or a name created exclusively by that retailer. In some cases, a retailer may belong to a wholesale group that owns the brands that are available only to the members of the group."

${ }^{2}$ For a recent review of this literature, see Berges et al.(2004).
} 
surplus. Hausman and Léonard (2002) pointed out that consumers surplus is affected through two ways: a variety effect and a price effect. The classical result is that an additional product increases competition and then decreases prices. However, the price decrease is not always verified. For example the introduction by a multi-product firm of a new product may lead to an increase in the price of the existing products as the firm takes into account the interaction between all products 3 If the introduction of private labels is accompanied by an increase in prices of existing brands, the impact on consumers' surplus (through prices) could be negative or at least significantly reduced.

From a theoretical point of view, Gabrielsen and Sørgard (2007) showed that under some circumstances the introduction of private labels decreases both consumer and total welfare. In that case the price of existing products increases with the entry of private labels 4 In the pharmaceutical industry, the entry of generic product (when patent expires) causes similar phenomena. Research on the US market showed that the introduction of a generic product frequently causes an increase in the price of the incumbent product (e.g. Frank and Salkever, 1997). The generic product attracts switching consumers while the incumbent product concentrates on the inelastic part of the demand which explains the price increase. According to Frank and Salkever, the increase in price is not 'sufficient' to annihilate the positive impact on consumer welfare of the entry of a generic product. This increase in price is however not systematic as exemplified by the analysis of Bergman and Rudholm (2003) on the pharmaceutical market in Sweden.

To sum up, there still exists some uncertainty on the PL price effect. If PL development is accompanied by NB price increase, then the consumer surplus could be negatively affected or at least the anticipated gain for consumers (of a PL development) could be very low. This is an empirical question that needs to be further investigated. The present study generalizes and extends the approach developed by Bontemps et al. (2005). Firstly, theoretical models suggest that the positioning of private labels is a key element in the strategy of a retailer (ScottMorton and Zettelmeyer, 2004, Bontems, 2005). It is now well established by marketing studies that there are at least three types of private labels ('low price', 'me-too' and 'high quality'). These different private labels are targeted to compete with a specific class of products. In broad terms, the 'low-price' category

\footnotetext{
${ }^{3}$ With the new product, the marginal loss of revenues due to an increase in the price of existing products is lowered as part of the lost demand is now attracted by the new product. The firm has thus interest to increase the prices of existing products.

${ }^{4}$ Note however that under some circumstances the prices of existing brands increase as well as consumer and total welfare.
} 
is a response of the major retailing chains to the development of hard discount stores. Therefore, retailers use private labels preferentially for competition to attract switcher consumers. The 'me-too' products are the private labels used by retailers to compete with national brands. They are used primarily to obtain more bargaining power in relation to the upstream producers. Finally, 'high-quality' products have been developed more recently by retailers in an attempt to build reputation, rather corresponding to a way of attracting new consumers (and thus dealing with competition among retailers). If these different categories of private labels were developed for various purposes, then changes in the prices of national brands due to the development of private labels should differ as a function of their type.

Secondly, theoretical models suggest that national brand producers could react to private labels development by a strategy of product differentiation and, in particular, by modifying 'quality' (Mills, 1999; Bontems, 2005). If this were true, then this would create a change in the price of national brands that reflects the change in the product characteristics rather than the pricing strategy. We thus need to separate the price effect for a given set of characteristics from the price change due to modifications in the characteristics.

Thirdly, recent studies have suggested that the different national brands could be differently affected by the entry of private labels. For example Scott-Morton and Zettelmeyer (2004) showed that, in a context of limited shelf space, a retailer introducing a private label will position it close to the leading brand. Moreover, they pointed out that the retailer will no longer sell the second-tier national brand. Sayman, Hoch and Raju (2002) also showed that the retailer should target the leading brand when introducing a private label. Both studies found some empirical evidence supporting their theoretical analysis. However, they also found cases in which private labels were not targeted towards the leading national brand. Du, Lee and Staelin (2006) developed a theoretical model that included three products (two national brands and one private label). They showed that, in many situations, it might be more profitable for the retailer to locate the private label close to the second national brand. Thus, we investigate here whether the prices of the different national brands are differently affected by private label development.

Our paper is thus one step to better understand the price effect of PL introduction taking into account both the heterogeneity of PL and the heterogeneity of NB. If NB prices increase with the introduction of PL it could be the case that consumer surplus is negatively affected by the development of PL. To address 
these issues, we use home-scanned data from a panel of consumers and study the links between prices of national brands and the development of private labels. In Section 2, we briefly summarize the main findings of the recent literature. Then, Section 3 presents the model used to estimate the links between private labels development and national brand prices in France. The data used are reported in Section 4. Section 5 presents the empirical models that are estimated. We discuss the results in Section 6 and give our conclusions in Section 7.

\section{An overview of recent empirical studies on the im- pact of private labels development}

Recent empirical studies have investigated the impact of private label development on prices. Ward et al. (2002) studied the impact of the development of private labels in the US. These authors used monthly data on prices, market share and advertising expenses for 32 product categories. For each category, they analysed how national brands react to the development of private labels. They showed that an increase in the private label market share is consistent with:

- An increase (or no change) in the price of national brands .

- A decrease (or no change) in the price of private labels.

- A decrease or no change of average prices.

- A decrease in advertising activity for national brands.

Using the same methodology, Bontemps et al. (2005), using French data on 6 dairy products, showed that an increase in the private label market share is consistent with an increase in the price of national brands. Gabrielsen et al. (2002) investigated the impact of the introduction of private labels in Norway for 83 products. For each product, these authors studied changes in national brand prices over time and distinguished the period before the entry of private labels from the period after entry. When the impact of private labels introduction is significant (17 cases out of 83 products) there is a positive correlation (15 cases). The introduction of private labels produces an increase in national brand prices. This is in line with the idea that, after the entry of a private label, the national brand focuses on 'brand addict' consumers, while the PL is targeted towards 'switcher' consumers (Gabrielsen and Sørgard, 2007). Moreover, their results suggest that the increase in national brand prices is larger for leading and nationally distributed brands. 
These three studies concluded that private label development has a positive impact on national brand prices. However, Chintagunta, Bonfrer and Song (2002), using data on sales from different stores of a large supermarket chain, studied the impact of the introduction of private labels in the breakfast cereal market. They showed that private label introduction leads to a decrease in the price of the leading national brand, a decrease in the promotional activities of the national brand and no change in the profit margin of the retailer on the national brand. Bonfrer and Chintagunta (2004) analysed the impact of PL entry in 35 product categories. In about half of the cases surveyed (19 out of 35 cases), their study found that the entry of private labels leads to an increase in national brand prices. However, in the remaining cases, it leads to a price decrease 5

As explained previously, the entry of generic products in the pharmaceutical sector also leads to mixed empirical results. While Frank and Salkever (1997) provided evidence that the entry of generic products was accompanied by an increase in NB prices, Bergman and Rudholm (2003) found the opposite result in the case of the Swedish pharmaceutical market.

These studies mainly evaluated the effect of private labels development on national brand prices, considering private labels as one homogeneous group and national brands as another. However, as discussed in the introduction, the different types of private labels might compete in a different way with national brands. Similarly, the different national brands might be differently affected depending on the exact positioning of the private labels. Thus, a more detailed analysis of the impact of private label development on prices is needed. Ward et al. (2002) tested for different changes in the prices of the different national brands. They failed to find any strong evidence that the prices of the different national brands were affected in different ways. On the contrary, they concluded that, whether or not the NB is leader, the price effect is identical. Bontemps et al. (2005), demonstrated that the national brand prices vary according to the type of private labels they are facing. These authors also proposed that the price increase in national brand products could be partly explained by a strategy of product differentiation. Finally, Pauwels and Srinivasan (2004) showed there can be differences between the price changes of leading national brands and second-tier brands. They found an increase in the price of leading brands while, in some cases, they recorded a decrease in the price of second-tier brands after the entry of a private label.

\footnotetext{
${ }^{5}$ Bonfrer and Chintagunta (2004) also studied the impact of the entry of a competing national brand. They obtained a similar result, observing an increase in the price of incumbent national brands in 34 cases out of 65 .
} 


\section{Model}

In the literature, two main classes of models were estimated depending on the available data: consumer panels (home-scanned data) and retailer panels (e.g. scanner data). In the latter case, information on prices and sales is recorded for different stores. Then, researchers can observe and monitor the entry of a given private label as well as record the evolution of prices. When using such data, researchers commonly evaluate the price effect of entry by using dummy variables that indicate whether or not a private label is present (e.g. Gabrielsen et al. (2002)). The coefficient of the dummy variable provides information about the price effect. The specified models can be expressed as follows:

$$
\ln \left(P_{t}\right)=\alpha+\beta^{\prime} X_{t}+\gamma I_{[t>P L \text { date entry }]}+\varepsilon_{t}
$$

where $P_{t}$ is the NB price at time t, $X_{t}$ are various variables describing the market, including or not PL market shares.

On the contrary, with consumer panel data, researchers do not have precise information on prices in a given store. The price of a particular product in a given store is known only when at least one consumer of the panel has actually bought this product at that store. Thus, contrary to the previous case, it is now impossible to determine the behaviour of prices in a given store after the entry of a PL.

Moreover, with such a database, one cannot determine precisely when a new private label is introduced into a given store. The situation is comparable to a "continuous entry" of PL over time where it is only possible to observe the evolution of the PL market share. Thus, researchers generally analyse the price effects of PL development using a reduced form regressing the prices of national brands on various variables (e;g. Ward et al. (2002)). The model specified in this case can be formulated as follows:

$$
\ln \left(P_{t}\right)=f\left(X_{t}\right)+\varepsilon_{t}
$$

As we have access to consumer panel data we follow the second strategy described above. Because there is no single clear picture of the impact of private labels development on national brand prices, we test different models in a reduced form. We investigate the effects of the development of different types of private labels on the average price of national brands and the price of main national brands. We propose a general reduced-form specification for each product category $k \in\{1, \cdots, K\}$ : 


$$
\ln P_{k}^{i}=\beta_{0}+\sum_{j=1}^{J} \beta_{k, j} \cdot \ln M S_{k}^{j}+\sum_{q=1}^{3} \alpha_{q} \cdot d_{q}+\varepsilon_{k}^{i}
$$

where $P_{k}^{i}$ represents the monthly sequence of prices $P_{k}^{i}=\left(P_{k, 0}^{i}, \cdots, P_{k, T}^{i}\right)$ of the $i^{\text {th }}$ national brand price for the product category $k, M S_{k}^{j}=\left(M S_{k, 0}^{j}, \cdots, M S_{k, T}^{j}\right)$ is the sequence of market shares for the $j^{\text {th }}$ private label $(j \in 1, \cdots, J)$ for the product category $k$, and $d_{q}$ are the quarterly dummies, $\beta_{0}$ a constant parameter, and $\varepsilon_{k}^{i}$ the error term.

The price of a product k may change because its characteristics vary over time. It is a classical problem national statisticians face when computing price indexes. To deal with this issue, we define a segmentation of each product category in subcategories and compute the Paasche price index using volume of each subcategory at time $\mathrm{t}=0$. The assumption is that the characteristics of each subcategory is constant over time while the aggregate characteristics of the product category is not, as the share of each subcategory may change over time. The Paasche price index controls this effect. Thus, in equation 1, the Paasche price index (defined using a segmentation of each product category $k$, into $S_{k}$ sub-categories) is used as the alternative dependent variable. Formally, the Paasche price index sequence $\widetilde{P}_{k}^{i}=\left(\widetilde{P}_{k, 0}^{i}, \cdots, \widetilde{P}_{k, T}^{i}\right)$ is defined as:

$$
\widetilde{P_{k, t}^{i}}=\frac{\sum_{s=1}^{S_{k}} P_{s, t}^{i} \cdot \operatorname{Vol}_{s, 0}^{i}}{\sum_{s=1}^{S_{k}} \operatorname{Vol}_{s, 0}^{i}}
$$

In Section 5, we specify precisely the seven different models that are estimated.

\section{Data and descriptive statistics}

We used data from the TNS-SECODIP Consumer Panel, providing information on household purchases on 218 product categories over four years (1998-2001) in France 6 A more in depth analysis is proposed on a subset of 20 product categories. We defined $T=52$ periods of 4 weeks over the whole period. For each

\footnotetext{
${ }^{6}$ TNS-Secodip (Société d'Etudes de la Consommation, de la Distribution et de la Publicité) collects weekly data on purchases in more than 8,000 French households.
} 
product category $k$, we constructed a monthly time series of prices and market shares for the different types of brands. They are defined as follows:

- The price of the NB brand $i$ at period $t, P_{k, t}^{i}$, is defined as the ratio between the sales and the volume of purchases of brand $i$ during the given period. It is deflated using the consumer price index or, when feasible, using a sector specific price index 7

- The Paasche price index is computed according to equation 2 on the basis of a case-by-case segmentation of each product category $k$ into $S_{k}$ subcategories.

- The market share of brand $j$ for product $k$ at period $t, M S_{k, t}^{j}$, is the ratio of the volume of brand $j$ purchased during the period to the volume of all brands purchased in the same period. We define five main types of brands. The first two are traditionally considered as private labels, the third corresponds to low-price products, while the last two are producer brands. They are sequentially defined as follows:

HD : Hard Discount products are sold exclusively by hard discounter stores 8 .

PL : Private Labels (sensu stricto) are developed exclusively by retailers. Within this category we distinguish three subtypes i.e. :9]

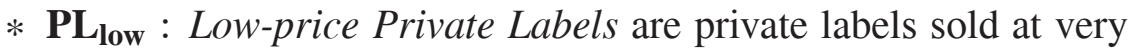
low prices,

* PL $_{\text {stand }}$ : Standard Private Labels. In particular, 'me-too' products belong to this category,

* $\mathbf{P L}_{\text {prem }}$ : Premium Private Labels are private labels of 'high quality'.

FP : First Price products are brands sold at low prices. We define them as brands that are neither HD nor PL, and whose price is lower than or equal to the price of HD products. They are generally considered as

\footnotetext{
${ }^{7}$ For some products for which the value of the agricultural raw material is a significant part of the final value (e.g. fluid milk, cream) we use a production price index instead of the general consumers price index.

${ }^{8} \mathrm{~A}$ discount store is a "low cost" retail store, which sell mostly food products at low prices. The store proposes less choices and almost no national brands. The items are generally proposed in rough boxes instead of shelves.

${ }^{9}$ We define these subtypes of PL using information on PL names and prices in each retail chain.
} 
the response of supermarkets and hypermarkets to the development of hard discounters. However they are not private labels since they are producer brands that are not specific to a particular retailer.

Theremaining brands are producers brand. We distinguish :

* NB : National Brand products that are sold in more than $50 \%$ of French regions. For each product category, we also define the first three leading brands, $N B_{1}, N B_{2}$ and $N B_{3}$, based on market share by volume.

* RB : Regional Brand products are other brands sold in less than $50 \%$ of French regions.

In the following, we present some descriptive statistics for the 20 product categories which are more systematically analysed in this study. On Figure 1, national

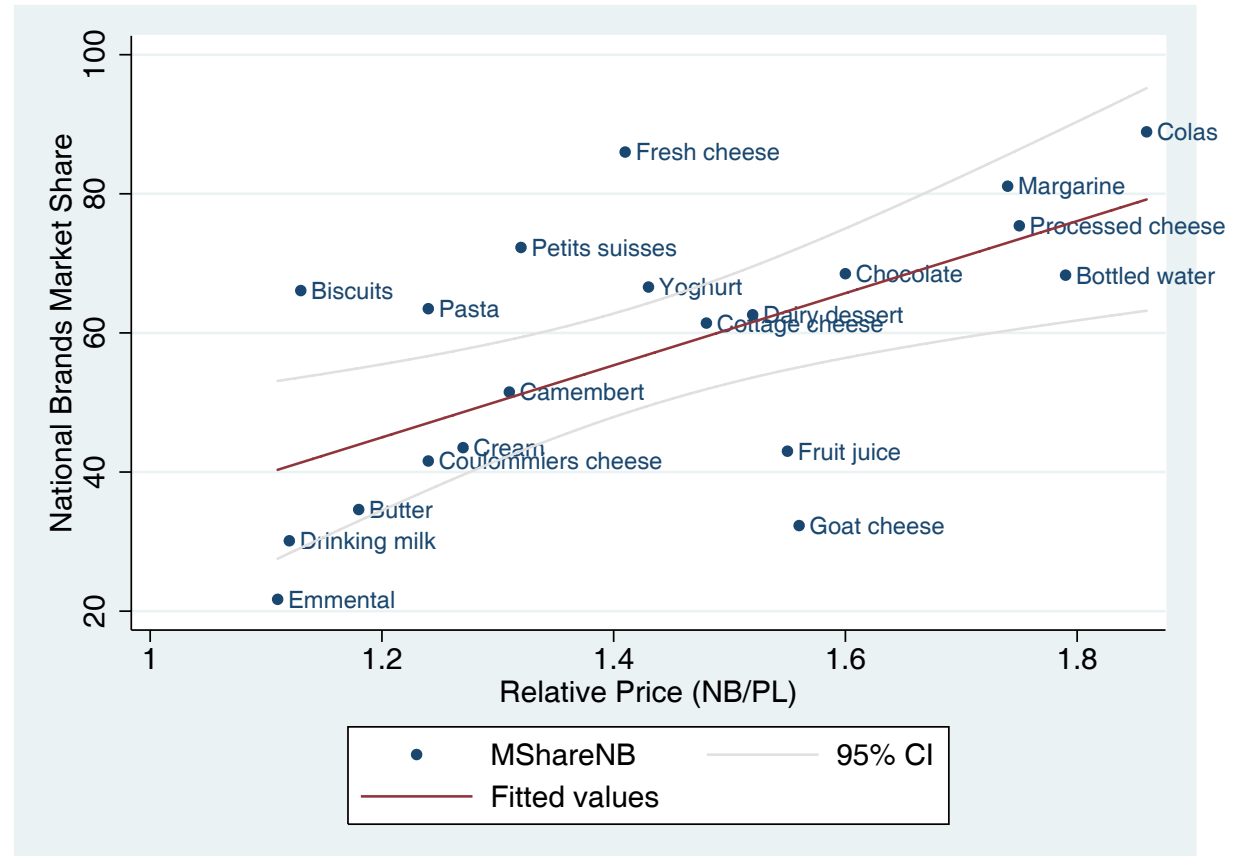

Figure 1: National Brands Market Share vs Relative Price

brand market shares are plotted against relative prices, defined as $P_{N B} / P_{P L}$. We note a significant $(\mathrm{p}$-value $=0.006)$ and positive correlation between the national 
brand market share and the relative price 10 Although this relationship appears counter-intuitive, it is consistent with the analysis developed by Mills (1995) that takes into account the differentiation between national brands and private labels. As explained by Mills (1995, p.523) of his article, "In a cross section of product categories where retailers sell both national brands and private labels, the private labels' share of category unit sales (...) vary inversely with $\Delta_{p}$ (difference in national brand and private label prices) 11 Thus, when the national brand market share is low, this means that the consumer does not perceive quality differences between national brands and private label products. Hence, the price competition is 'tough'. Then, even if the price difference between NB and PL products is relatively small, the NB market share is small too due to the lack of product differentiation. On the contrary, if the national brand is perceived to be of significant higher quality, then a 'large' difference in price is compatible with a large market share for national brands 12

Table 1 presents some statistics for private labels (PL+HD) and national brands for the 20 product categories. Within each category, the national brand product price is higher than the average price (set at the index 100). Conversely, the private label price is lower than the average price in most cases. The market shares of national brand products vary greatly across categories (from $18 \%$ for Emmental cheese up to around $80 \%$ for colas and fresh cheese). Private label market shares are less variable and rarely reach $50 \%$ (ranging from $14.3 \%$ for fresh cheese to $61 . \%$ for fruit juice).

The change of market share over time ( $\rho$ in Table 1 ) reveals a significant development of private labels over the period. For almost all the product categories, the trend coefficient of private labels $(\mathrm{PL}+\mathrm{HD})$ market share is significant and positive 13 The average growth of private label market share is greater than $1 \% 0$ per period on several markets, even reaching 3\% for some products 14

\footnotetext{
${ }^{10} \mathrm{We}$ obtain a similar result using the whole set of product categories (218).

${ }^{11}$ In Figure 1, we report the NB market share, and not the PL market share as in Mills (1995), thus explaining the positive correlation obtained here.

${ }^{12}$ We obtain a similar result using all the product categories.

${ }^{13}$ This result is confirmed by an exhaustive analysis of 218 products showing that, out of 156 cases with significant trend coefficients for the private labels market share, $134(86 \%)$ exhibit a positive sign.

${ }^{14} \mathrm{~A} 1 \%$ increase per period is equivalent to $1.3 \%$ increase per year ( 13 periods of 4 weeks per year). A $3 \%$ increase per period is equivalent to a $4.0 \%$ increase per year.
} 


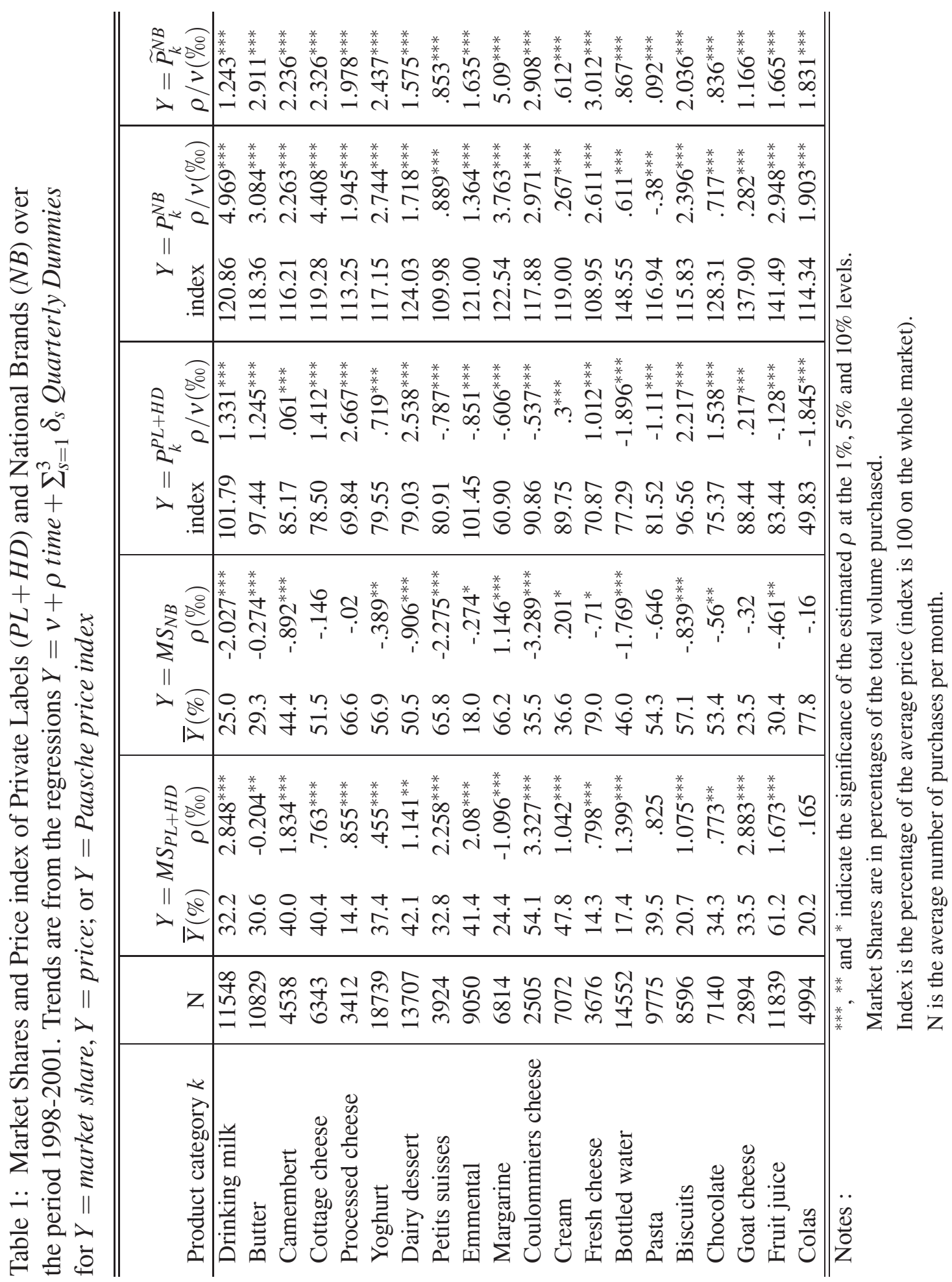


Conversely, the national brand market share decreases in most cases and it increases in only two product categories (margarine and cream).

With respect to prices, we define the ratio $\rho / v$ as a trend coefficient approximating the rate of growth of the price per-period evaluated for the first period 15 It is noteworthy that the trend coefficient of national brand prices is significant and positive for all product categories but one. Thus, national brand prices usually increase by more than $1 \%$ up to $4 \%$ per period of 4 weeks (that is 1.3 to $5.3 \%$ per year) 16 Using the Paasche price index instead of the price reveals the same pattern here, trends being positive for all products.

For some products (drinking milk, cottage cheese, fruit juice), the Paasche price index increases at a much lower rate than the observed price. It means that part of the increase in observed price is due to a change in the 'composition' of the product (the relative share of 'high quality' subcategories increased over time). However, for some other products there is no difference. For margarine, it is the opposite which would imply that NB products are more present in 'low quality' subcategories at the end of the period.

\section{Empirical models}

In table 2, we present the 7 different models that are estimated in this paper. All models are derived from the general model defined in Equation (1). We consider various sets of private labels as explanatory variables, combined with decomposed or aggregated definition of National Brands. In the following, we use the tilde superscript to denote models where the price on the left hand side is replaced by the Paasche price index of the price :

Model M1 is similar to the model estimated by Ward et al (2002) and is estimated for all products available (218). We establish this simple model in order to compare our results with their results obtained on the US market. Model $\widetilde{M 1}$ is similar to model M1 except that the left hand side of the model is a Paasche price index controlling for changes in the price of national brands due to a change in the pool of goods that make up a product category. It is estimated on a reduced set of products categories (20) for which a segmentation has been performed. Models M2 and $\widetilde{M 2}$ are developed to test whether or not different brands (Private Labels

\footnotetext{
${ }^{15}$ That is the ratio between the coefficient of the linear trend and the value of the constant.

${ }^{16}$ This result is also confirmed on the 218 product categories, since $87 \%$ of the significant trend coefficients are positive.
} 
Table 2: Empirical models estimated

\begin{tabular}{|c|c|c|c|}
\hline$\overline{\text { Models }}$ & $\begin{array}{l}\text { Dependent } \\
\text { variable }\end{array}$ & Set of Private labels & $\begin{array}{c}\text { Number of products } \\
\text { examined }\end{array}$ \\
\hline M1: & $\ln P_{k}^{N B}$ & $j \in\{P L+H D\}$ & $N=218$ \\
\hline$\widetilde{M 1}:$ & $\ln \widetilde{P}_{k}^{N B}$ & $j \in\{P L+H D\}$ & $N=20$ \\
\hline M2: & $\ln P_{k}^{N B}$ & $j \in\{P L, H D, F P\}$ & $N=218$ \\
\hline$\widetilde{M 2}$ & $\ln \widetilde{P}_{k}^{N B}$ & $j \in\{P L, H D, F P\}$ & $N=20$ \\
\hline$\widetilde{M 3}$ & $\ln \widetilde{P}_{k}^{N B}$ & $j \in\left\{P L_{\text {low }}, P L_{\text {stand }}, P L_{\text {prem }}, H D, F P\right\}$ & $N=14$ \\
\hline$\widetilde{M 4}$ & $\begin{array}{l}\ln \widetilde{P}_{k}^{N B_{1}} \\
\ln \widetilde{P}_{k}^{N B_{2}} \\
\ln \widetilde{P}_{k}^{N B_{3}} \\
\end{array}$ & $j \in\{P L, H D, F P\}$ & $N=20$ \\
\hline$\widetilde{M 5}$ & $\begin{array}{l}\ln \widetilde{P}_{k}^{N B_{1}} \\
\ln {\widetilde{P^{N}}}_{k}^{N B_{2}} \\
\ln \widetilde{P}_{k}^{N B_{3}} \\
\end{array}$ & $j \in\left\{P L_{\text {low }}, P L_{\text {stand }}, P L_{\text {prem }}, H D, F P\right\}$ & $N=14$ \\
\hline
\end{tabular}

sensu stricto, Hard Discount products and First Price brands), have a different effect. In Model $\widetilde{M 3}$ (and $\widetilde{M 5}$ ), we further analyse the role of private labels by distinguishing three types of private labels. Because the definition of these three types of private labels is based on the analysis of their prices within a particular retailer, we restrict our analysis to the three largest retailers 17 Finally, in Models $\widetilde{M 4}$ and $\widetilde{M 5}$, we analyse if the prices of the different national brands are differently affected by the development of private labels.

Since market shares may be endogeneous, we perform the estimation of all the empirical models with respect to this problem. Here, potential endogeneity is in principle mainly related to the demand. We thus selected exogeneous instruments

\footnotetext{
${ }^{17}$ The three largest retailers in France represent more than $40 \%$ of total sales. We worked on 14 products rather than 20 because, in some cases, at least one of the retailers doesn't have all types of private label.
} 
with explanatory power on the market shares: the lagged PL market share for each type of private label for the current product category, the private label market share for other products, as well as other characteristics of the market (number of producers, number of brands, market size relative to other products, market concentration, etc.). These instruments should explain time and cross-sectional patterns of market shares of private label in one category driven by factors that drive general average "growth" in private label in other categories. Thus, the instrumental variables estimation performed is netting out what could have been due to endogenous determinants of private labels market shares 18 So, for each product category, we first test for relevance and validity of the instruments using the Sargan overidentification test 19 Then, using Hausman's test, we test for endogeneity and apply instrumental variables estimation if needed.

For each empirical model, we also test for autocorrelation and heteroskedasticity that may have arisen from the computation of average prices and market shares on each period and correct the estimation according to the results of the tests 20

\section{Results}

Question 1: Do the National Brands prices rise with the development of Private Labels?

From Model M1, we conclude that the development of private labels coincides with a significant increase in national brand prices (Table 3). This result is in line with the findings of Ward et al. (2002), even though our study covers a larger number of product categories and was carried out in a different country.

National brand producers may react to private label development either by using a product differentiation strategy, or by developing new products. In that case, the 'average quality' of national brands might increase over time because producers focus on 'high quality' products. Such a change in quality might also

\footnotetext{
${ }^{18}$ Endogeneity may also arise from (unobserved) costs. The instruments used here may also be valid with this source of endogeneity (e.g. private labels market shares for other products).

${ }^{19}$ We use Stata's IVREG2 procedure and test the relevance of the instruments by checking their significance on the first-stage regression.

${ }^{20}$ We use the White and Breush-Pagan heteroskedasticity tests and the Breusch-Godfrey test for higher-order serial correlation in the error distribution.
} 
Table 3: Number of positive $\beta$ in Model M1 on the 218 product categories

\begin{tabular}{l|c|c|cc}
\hline \hline & & Significant & \multicolumn{2}{c}{ Positive } \\
\hline Model M1 & $\beta_{P L+H D}$ & 116 & 103 & $(89 \%)$ \\
\hline \multicolumn{3}{c|}{ Detailed results on the 20 products categories are gathered in Table $\mathrm{A}-1$}
\end{tabular}

explain the increase in NB average price observed in Table 1. This leads us to ask:

Question 2: When quality effects are taken into account, do the National Brands prices still rise with Private Labels development?

As explained above, to control for quality changes, we used a Paasche price index instead of the average price. Doing that we control for changes in the average price of a product category that results from a change in the share of the different subcategories of this product category. We use the Paasche price index for NB prices as dependent variable in Model $\widetilde{M} 1$.

The coefficients for model $\widetilde{M} 1$ are all significant and positive in 18 cases over 20 (Table A-1) 21 This means that the policy of NB producers to focus more on specific subcategories (which is frequently the case) does not fully explain the increase in the price of NBs. Thus, it is likely that quality changes are not enough to explain the increase in NB prices.

Previous empirical studies did not consider the differences between Private Labels and Hard Discount brands. However, the price effects of the development of private labels and hard discount products may not be identical. Indeed, these two brands are developed by retailers for different purposes. Moreover, in the case of competition between PL and NB, the same retailer sets both prices, while HD retailer only sets the price of HD products (as this retailer does not sell NB).

Question 3: Are there differences between the price effects of Private Label, Hard Discount and First Price products?

Our results show that the development of the different types of retailer brands has significant price effect. We find more frequently a significant value for private

\footnotetext{
${ }^{21}$ They are negative for butter and margarine which are the only products experiencing a decrease in the market shares of PL (see Table1).
} 
Table 4: Number of positive $\beta$ values in Model M2 on 218 product categories

\begin{tabular}{l|l|c|cc}
\hline \hline & & Significant & \multicolumn{2}{c}{ Positive } \\
\hline \multirow{3}{*}{ Model M2 } & $\beta_{P L}$ & 108 & 99 & $(91 \%)$ \\
& $\beta_{H D}$ & 89 & 79 & $(89 \%)$ \\
& $\beta_{F P}$ & 73 & 57 & $(78 \%)$ \\
\hline \hline
\end{tabular}

See Table A-1 for the results, on Models M2 and $\widetilde{M 2}$, on the 20 product categories

labels than First price products. Moreover, when significant the impact of the three types of retailer brands is positive (Table 4). The ranking of the effects shows that when significant, as observed in 2/3 of the cases, Private Labels (sensu stricto) have the largest impact (Table 5) 22

Table 5: Comparison of the $\beta$ values obtained with Model M2

\begin{tabular}{lc|ccc|c}
\hline \hline & & \multicolumn{3}{|c|}{$\beta_{H D} \leq \beta_{P L}$} & \\
& & False & True & N. S. & \\
\hline \multirow{3}{*}{$\beta_{F P} \leq \beta_{P L}$} & False & 11 & 2 & 5 & \\
& True & 5 & $\mathbf{9 6}$ & 5 & \\
& N.S. & 15 & 5 & 0 & \\
\hline & & & & & 144 \\
\hline \hline
\end{tabular}

Test for 144 products having at least one significant $\beta$ in Model M2

Details of the test for the 20 product categories are in Table A-1

To summarize, we obtain the following inequalities:

$$
\begin{aligned}
& \beta_{H D} \leq \beta_{P L} \\
& \beta_{F P} \leq \beta_{P L}
\end{aligned}
$$

Thus, the elasticity of NB prices with respect to market share of PL is always greater than (or at least equal to) the elasticity with respect to HD or FP. However, it is not possible to systematically rank the respective elasticity with respect to HD

\footnotetext{
${ }^{22}$ We use the Wald test of equality between $\beta$ 's in Models $M 2$.
} 
and FP. Note that, when quality changes are taken into account (model $\widetilde{M 2}$ ), the above inequalities still hold (Table A-1).

The models tested so far yield robust results with respect to the sign of the $\beta$ coefficient as well as their ranking, whatever the products. However, the $\beta$ values differ from one category to another. We thus attempted to find some market characteristics that could explain the differences in the $\beta$ values between product categories.

Question 4: Do the effects differ between products?

To answer this question, we first perform a cluster analysis of the product category in order to distinguish groups of products. Then we test the equality of the $\beta$ between clusters. To perform the cluster analysis of the product categories we used variables describing the market structure for each product as well as consumers' behaviour (Table A-2). The clustering exhibits two groups of products 23 Cluster 1 includes 73 product categories for which the market is concentrated and experiencing a smaller private-label market share. Cluster 2 includes 71 products characterized by a lower concentration, a larger number of private labels, more brands and varieties of products .

Table 6: Equality tests and statistics on the $\beta$ 's in each cluster

\begin{tabular}{l|c|cc|cc|c}
\hline \hline & & \multicolumn{2}{|c|}{ Cluster 1 } & \multicolumn{2}{|c|}{ Cluster 2 } & \\
& & Mean & (s. e.) & Mean & (s. e.) & Equality Test \\
\hline Model M1 & $\beta_{P L+H D}$ & .077 & $(.0126)$ & .174 & $(.0289)$ & rejected \\
& & & & & & \\
& $\beta_{P L}$ & .078 & $(.0115)$ & .189 & $(.0284)$ & rejected \\
Model M2 & $\beta_{H D}$ & .042 & $(.0069)$ & .072 & $(.0156)$ & accepted \\
& $\beta_{F P}$ & .050 & $(.0170)$ & .042 & $(.0133)$ & accepted \\
\hline \hline
\end{tabular}

The equality test performs t-test on the equality of means between the 2 clusters. The result of the tests are given at a $95 \%$ confidence level.

The equality tests of $\beta$ between the two clusters show there are differences

\footnotetext{
${ }^{23}$ We use the Calinski and Harabasz index for the choice of the number of Clusters.
} 
between $\beta_{P L+H D}$ in Model M1 and $\beta_{P L}$ in Model M2 (Table 6). When the market is less concentrated (cluster 2), the value of $\beta_{P L}$ (or $\beta_{P L+H D}$ ) is larger. Thus, frequently-bought products with a large number of varieties, which have a high market share for private labels, are products associated with PL development along with a larger increase in national brand prices.

\section{Question 5 : Do all private labels have the same effects?}

As explained in the introduction, there exist at least three categories of private labels. All of them undergo a significant increase over time in their market share. Results show that the 'standard' private labels $\left(P L_{\text {stand }}\right)$ and the 'low-priced' private labels $\left(P L_{\text {low }}\right)$ have a significant and positive impact on NB prices (Table A-3). On the contrary, we did not find any significant effect due to premium private labels $\left(P L_{\text {prem }}\right)$. These results also suggest that the market shares of 'lowpriced' and 'premium' private labels are less correlated with NB prices than standard PL (i.e. $\beta_{P L_{\text {stand }}} \geq \beta_{P L_{\text {prem }}}$ and $\beta_{P L_{\text {stand }}} \geq \beta_{P L_{\text {low }}}$ ). This supports the hypothesis that these two categories of PLs are used to attract new consumers or build the reputation of retailers, and are less used as a strategic tool to compete with national brands. Conversely, the standard PL is more directly used as a tool to compete with NBs and thus its market share exhibits a stronger correlation with NB prices.

Till now, we have analysed the behaviour of the average price of national brands when private labels are developed. As suggested by theoretical studies (Scott-Morton and Zettelmeyer (2004); Du, Lee and Staelin (2006)), the different national brands might be differently affected 24

Question 6: Are each of the three leading national brands affected identically?

Professionals frequently argue that, with private labels development, secondtier national brands suffer more than leading brands. In this view, shelf space is scarce. Thus, when a retailer introduces a private label into a store, this leads to the removal of a national brand. The retailer may remove the $N B_{2}$ or $N B_{3}$ rather than the $N B_{1}$ (exactly as shown by Scott-Morton and Zettelmeyer, (2002)). However, a descriptive analysis (Table A-4) does not support this view. Thus, statistical tests

\footnotetext{
${ }^{24}$ Ward et al. (2002) investigated this question, but failed to find any significant differences between the brands.
} 
Table 7: Inequalities between $\beta$ coefficients

\begin{tabular}{cc|c}
\hline \hline & & $\beta_{P L} \geq \beta_{H D}$ and $\beta_{P L} \geq \beta_{F P}$ \\
\hline \multirow{3}{*}{ Model $\widetilde{M 2}$} & All NB & 17 cases out of 20 \\
\hline \multirow{3}{*}{ Model $\widetilde{M 4}$} & $N B_{1}$ & 16 cases out of 20 \\
& $N B_{2}$ & 17 cases out of 20 \\
& $N B_{3}$ & 15 cases out of 20 \\
\hline
\end{tabular}

See Table A-5 for details. The results of the Wald tests are given at a 95\% confidence level.

yield no evidence that $N B_{2}$ or $N B_{3}$ experience a larger decrease in market share than $N B_{1}$. Rather, we find that $N B_{1}$ experiences a larger decrease in market share than $N B_{3}$.

To test if the leading $N B s$ are differently affected by private label development, we developed the same models as before on each of three leading National Brands. First, we find that the results obtained for the aggregation of NB (i.e. $\beta$ s positive when significant and $\beta_{H D} \leq \beta_{P L}$ and $\beta_{F P} \leq \beta_{P L}$ ) still hold for each of the three leading national brands (see results of model $\widetilde{M 4}$ in Table 7 ) 25

Second, we estimated the price reaction of each leading NB to the development of each PLs. We find that the results obtained for the aggregation of NB (i.e. $\beta_{P L_{\text {stand }}} \geq \beta_{P L_{\text {prem }}}$ and $\left.\beta_{P L_{\text {stand }}} \geq \beta_{P L_{\text {low }}}\right)$ still hold for $N B_{1}, N B_{2}$ and in a lower extent for $N B_{3}$ (Table 8 ).

Finally, we tested the magnitude of the coefficients within the three leading national brands. In most of the cases, we obtain $\beta_{P L_{N B_{1}}} \geq \beta_{P L_{N B_{3}}}$ (Table 9). Thus, $N B_{1}$ and $N B_{3}$ prices behave differently. A possible explanation would be related to the strategic pricing of products by a retailer. If a private label is targeted against $N B_{1}$, a retailer might find it profitable to increase the price of $N B_{1}$ (in order to discriminate among consumers) by a larger amount than the prices of $N B_{2}$ and $N B_{3}$.

\footnotetext{
${ }^{25}$ Note that the $\beta_{F P}$ are less frequently significant and even sometimes negative.
} 
Table 8: Wald Test results of the equality of $\beta_{P L_{\text {stand }}}, \beta_{P L_{\text {low }}}$ and $\beta_{P L_{\text {prem }}}$ for all brands (Model $\widetilde{M 3}$ ) and each of the three leading brands (Model $\widetilde{M 5}$ )

\begin{tabular}{l|c|ccc}
\hline \hline & $\widetilde{M}$ & & $\widetilde{M 5}$ & \\
Null hypothesis $\left(H_{0}\right)$ & $\widetilde{M 3}$ & \multicolumn{3}{|c}{} \\
& All NBs & $N B_{1}$ & $N B_{2}$ & $N B_{3}$ \\
\hline$\beta_{P L_{\text {stand }}} \geq \beta_{P L_{\text {prem }}}$ & 14 & 13 & 14 & 11 \\
$\beta_{P L_{\text {stand }}} \geq \beta_{P L_{\text {low }}}$ & 14 & 13 & 13 & 14 \\
$\beta_{P L_{\text {low }}} \geq \beta_{P L_{\text {prem }}}$ & 14 & 13 & 14 & 11 \\
\hline
\end{tabular}

Table 9: Comparison of $\beta_{P L}$ in the three leading brands

\begin{tabular}{|c|c|c|}
\hline \multirow{3}{*}{ Model $\widetilde{M} 4$} & Null hypothesis $\left(H_{0}\right)$ & True \\
\hline & $\beta_{P L_{N B 1}} \geq \beta_{P L_{N B 3}}$ & 15 \\
\hline & $\beta_{P L_{N B 1}} \geq \beta_{P L_{N B 2}}$ & 14 \\
\hline
\end{tabular}

\section{Concluding Remarks}

In this paper, we analyse the relationships between NB prices and PL market shares on a large number of products. To achieve this objective, we specify various models in a reduced form. The results obtained in this empirical analysis are remarkably robust. We detected a significant and positive correlation between private labels development and the prices of national brands. This confirms the results of Ward et al (2002) based on US data, and extend the study developed by Bontemps et al (2005). When taking the quality effect into account, we still find a positive relation between private label development and national brand prices. Thus, the change in the NB product characteristics is not the only reason for the increase in the NB prices.

Moreover, our results corroborate the additional hypotheses developed in this paper. Firstly, the impacts of the different brands (Private Labels sensu stricto, 
Hard Discount products and First Price brands) are not identical. Even if we found positive effects for each of the three brands, the increase in the national brand prices with the development of hard discount products or first-price products is lower than with the development of Private Labels.

Secondly, by carrying out a more detailed analysis within the private labels, we can show there is a different amplitude of the impact on prices. The standard private labels, which can be considered as 'me-too' products, have the strongest impact on national brand prices, while low-price private labels have a lower impact. The development of premium PL does not exhibit significant impact on NB prices. These results are consistent with the idea that standard PL were developed by retailers to compete directly with NB products.

Finally, our results suggest that the leading national brand prices are affected in different ways by private label development. Indeed, the development of Private Labels (sensu stricto) has less effect on the prices of second-tier brands than on the prices of the leading brand. A result that differs from Ward et al. (2002) who did not found any differences among NBs.

It should be understood that in this analysis we cannot elucidate if the increase in the retail price of NB is due to an increase of the wholesale price or is due to the strategy of retailers who choose both the assortment and prices (or both). Retailers when introducing or developing a private label may find some interest to increase the NB prices in order to discriminate among consumers.

Overall, our results provide some support to the analysis developed by Gabrielsen and Sørgard (2007) who showed that under some circumstances private labels development may induce an increase in NB prices. These results also suggest that the development of PL may have some negative impact on consumers surplus. At least the surplus of some consumers might be negatively affected.

The reduced-form modeling adopted here allows us to handle a large number of products and models. Nevertheless, the disadvantage of this approach is that it cannot provide in-depth explanations of the mechanisms involved. An alternative approach would be to develop structural models for testing the strategic behaviour of retailers. However, this would only be feasible on a reduced number of products.

\section{References}

Bergès-Sennou, F., P. Bontems, and V. Réquillart. "Economics of Private Labels: a Survey of Literature." Journal of Agricultural \& Food Industrial Organi- 
zation 2(2004): No. 2, article 3.

Available at http://www.bepress.com/jafio/vol2/iss1/art3

Bergman, M.A., and N. Rudholm."The relative importance of actual and potential competition: empirical evidence from the pharmaceuticals market" Journal of Industrial Organization LI-4(2003):455-467

Bonfrer, A., and P.K. Chintagunta. "Store brands: who buys them and what happens to retail prices when they are introduced?" Review of Industrial Organization 24(2004):195-218.

Bontems, P. "On the welfare impacts of store brands." INRA-ESR Toulouse (mimeo), 2005.

Bontemps, C., V. Orozco, A. Trévisiol and V. Réquillart. "Price Effects of Private Label Development", Journal of Agricultural \& Food Industrial Organization 3(2005): No. 1, article 3. Available at http://www.bepress.com/jafio/vol3/iss1/art3

Chintagunta, P. K., A. Bonfrer, and I. Song. "Investigating the effects of store brand introduction on retailer demand and pricing behaviour" Management Science 48(2002):1242-1267.

Du, R., E. Lee, and R. Staelin. "Bridge, Focus, Attack or Stimulate: Retail Category Managmeent Strategies with a Store Brand" Quantitative Marketing and Economics 3-4(2005). :393-418.

Frank, R.G., and D.S. Salkever."Generic entry and the pricing of pharmaceuticals” Journal of Economics and management Strategy 6-1(1997):75-90.

Gabrielsen, T. S., and L. Sørgard. "Private labels, price rivalry and public policy." European Economic Review. 51(2007):403-424.

Gabrielsen, T. S., F. Steen, and L. Sørgard. "Private labels entry as a competitive force? An analysis of price responses in the Norwegian food sector." Paper presented at the XII ${ }^{\text {th }}$ EARIE Conference, Madrid, Spain, August 2002. Available at http://www.uib.no/

Hausman, J.A., and G.K. Leonard. "The competitive effect of a new product introduction: a case study" Journal of Industrial Organization L-3(2002):237263.

INSEE. "Le commerce en 2004” INSEE Première 1023(2004).

Mills, D. E. "Private labels and manufacturer counterstrategies." European Review of Agricultural Economics 26(1999):125-145. 
Mills, D. E. "Why retailers sell private labels." Journal of Economics and Management Strategy 4(1995):509-528.

Pauwels, K. and S. Srinivasan "Who Benefits from Store Brand Entry" Marketing Science 23-3(2004):364-390.

Sayman, S., S. J. Hoch, and J. S. Raju. "Positioning of store brands." Marketing Science 21(2002):378-97.

Scott Morton, F., and F. Zettelmeyer. "The strategic positioning of store brands in retailer-manufacturer negotiations." Review of Industrial Organization 24(2004):161-194.

Ward, M. B., J. P. Shimshack, J. M. Perloff, and M. J.Harris. "Effects of the private-label invasion in food industries." American Journal of Agricultural Economics 84(2002):961-973.

\section{Appendix}




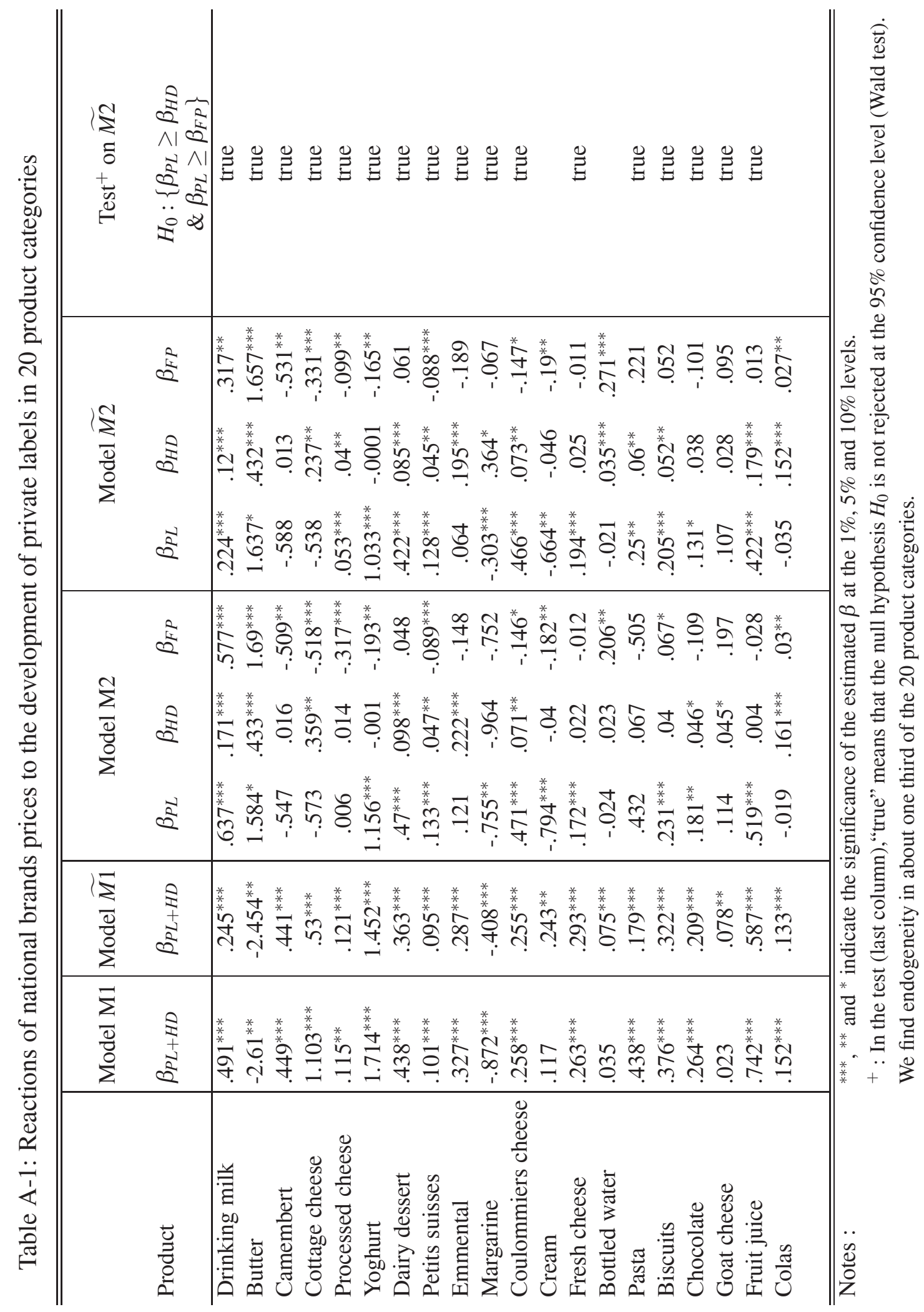


Table A-2: Variables describing the two clusters of products (Clustering analysis)

\begin{tabular}{|c|c|c|c|}
\hline Variables & $\begin{array}{c}\text { Cluster } 1 \\
\text { mean }\end{array}$ & $\begin{array}{c}\text { Cluster } 2 \\
\text { mean }\end{array}$ & $\begin{array}{c}\text { Equality Test } \\
(p \text {-value })\end{array}$ \\
\hline Market concentration (Herfindahl Index) & 1870 & 900 & $>\quad(0.0000)$ \\
\hline Number of NB & 7.16 & 19.65 & $(0.0000)$ \\
\hline Number of HD & 4.38 & 8.14 & $(0.0000)$ \\
\hline Relative PL price $\left(\frac{\text { Price }_{P L}}{\text { Market Price }}\right)$ & 97.42 & 92.53 & $=(0.2686)$ \\
\hline Relative HD price $\left(\frac{\text { Price }}{\text { Market Price }}\right)$ & 69.31 & 68.24 & $(0.6266)$ \\
\hline Market share of $\mathrm{HD}(\%)$ & 7.25 & 8.34 & $=(0.1245)$ \\
\hline Market share of FP $(\%)$ & 8.56 & 7.55 & $(0.5402)$ \\
\hline Trends in NB market shares $(\rho$ in $\%$ ) & -0.875 & -0.879 & $=(0.9890)$ \\
\hline NB Relative PL price $\left(\frac{\text { Price }_{N B}}{\text { Price }}\right)$ & 1.32 & 1.39 & $(0.1674)$ \\
\hline Coefficient of variation of the average price & 5.52 & 4.12 & $(0.0056)$ \\
\hline Loyalty to NB (share of NBs) & 0.56 & 0.46 & $>\quad(0.0018)$ \\
\hline \multicolumn{4}{|l|}{ Variables not included in the $P C A^{*}$} \\
\hline Market Share of PL $(\%)$ & 17.52 & 27.79 & $(0.0000)$ \\
\hline Market Share of NB (\%) & 60.34 & 50.97 & $(0.0034)$ \\
\hline Number of brands & 38.05 & 71.01 & $(0.0000)$ \\
\hline Number of $P L$ & 11.97 & 22.66 & $(0.0000)$ \\
\hline Number of producers & 27.31 & 45.75 & $(0.0000)$ \\
\hline Number of varieties & 99.34 & 154.55 & $(0.0326)$ \\
\hline Number of products & 73 & 71 & \\
\hline
\end{tabular}




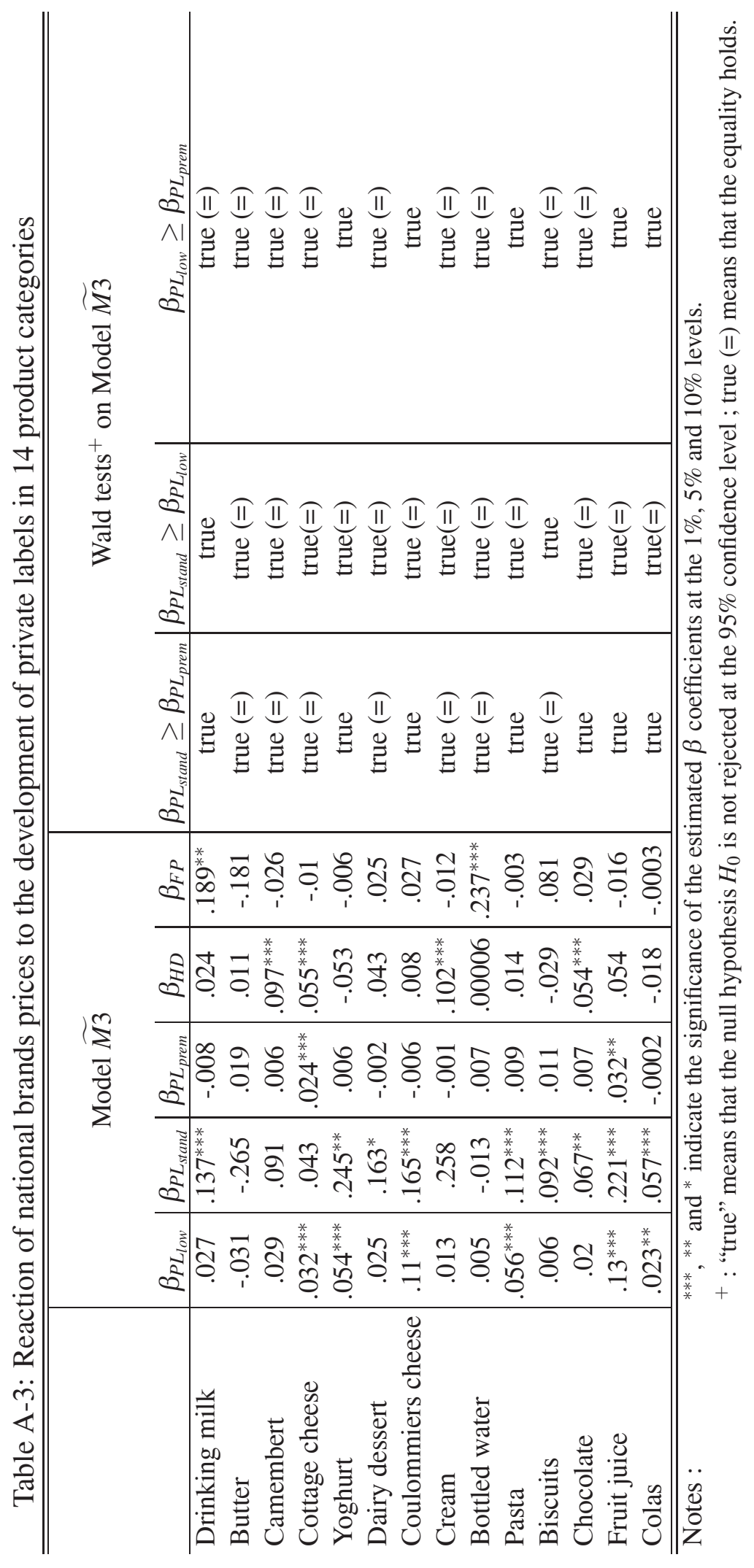




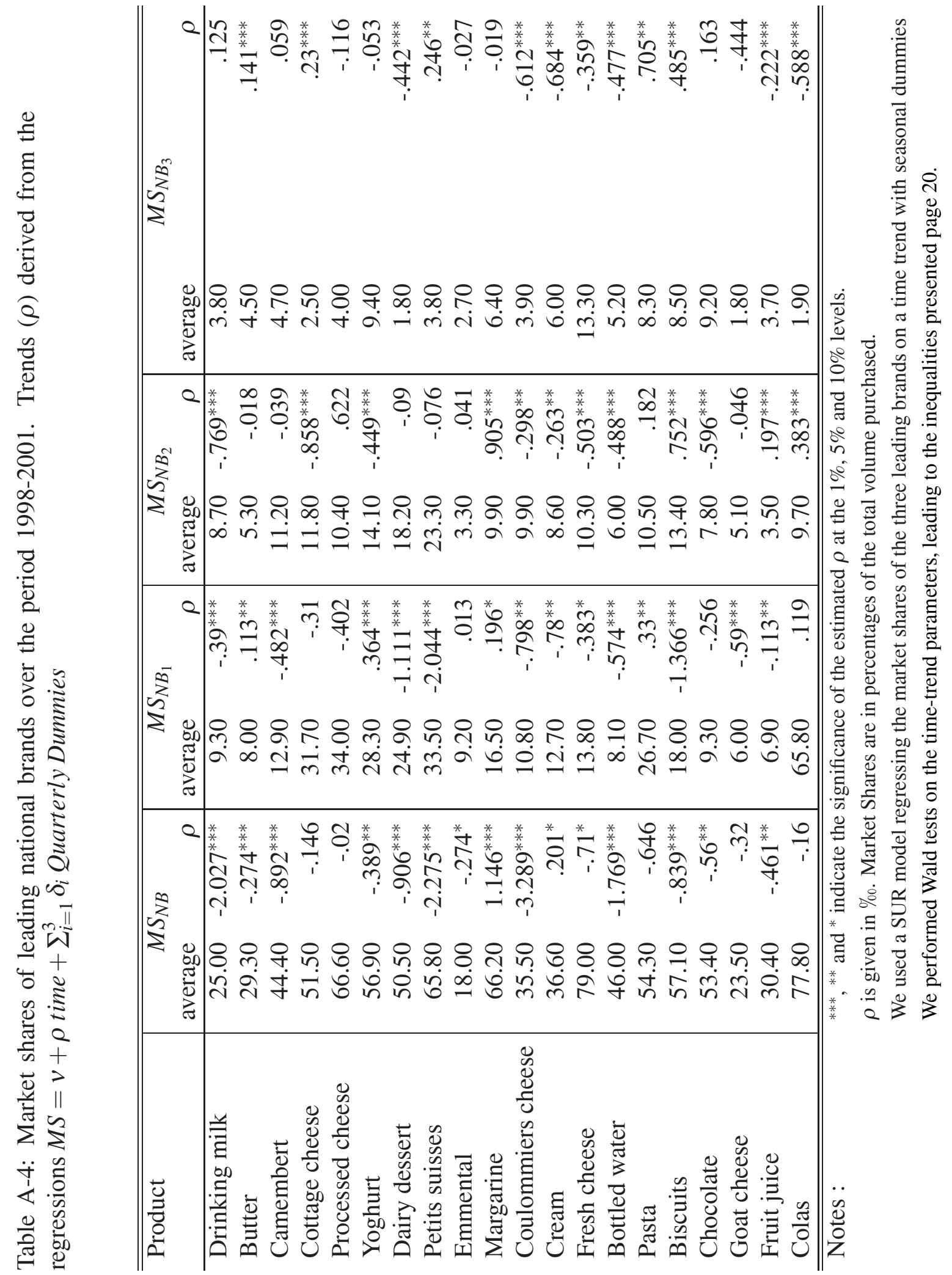


